Cite this: J. Mater. Chem. C, 2016, 4,6270

Received 15th May 2016 Accepted 4th June 2016

DOI: $10.1039 / c 6 t c 02009 g$

www.rsc.org/MaterialsC

\title{
Synthesis and molecular properties of methoxy- substituted diindolo[3,2-b:2',3'-h]carbazoles for organic electronics obtained by a consecutive twofold Suzuki and twofold Cadogan reaction $\dagger$
}

\author{
Hassan Srour, ${ }^{a}$ Thu-Hong Doan, ${ }^{a}$ Elisabeth Da Silva, ${ }^{a}$ Richard J. Whitby*b and \\ Bernhard Witulski*a
}

\begin{abstract}
A set of methoxy-substituted diindolo[3,2-b:2', $\left.3^{\prime}-h\right]$ carbazoles has been synthesized by twofold SuzukiMiyaura, Cadogan and $\mathrm{N}$-alkylation reactions starting from $\mathrm{N}$-hexyl-2,7-dibromo-3,6-dinitro carbazole. Microwave accelerated reactions ensure a rapid straightforward and step-ecomomic assembly of the diindolo[3,2-b:2', $\left.3^{\prime}-h\right]$ carbazole framework. Besides the parent diindolo[3,2- $\left.b: 2^{\prime}, 3^{\prime}-h\right]$ carbazole four new methoxy-group bearing derivatives were obtained and their molecular properties were investigated by thermal, photophysical and electrochemical means. Dichloromethane solutions of the diindolocarbazoles display with respect to the methoxy-group substitution pattern bright photoluminescences covering the blue to green spectra with quantum yields of $\phi_{\mathrm{F}}=0.20-0.27$. Notably, the $N, N, N$-tri- $n$-hexyl-1,4,9,12-

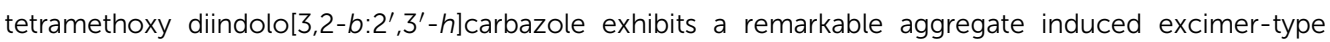
luminescence $\left({ }^{\mathrm{em}} \lambda_{\max }=562 \mathrm{~nm}\right.$, $\left.{ }^{\text {solid }} \phi_{\mathrm{F}}=0.14\right)$ in the solid state resulting in bright yellow light emission, whereas the parent non-substituted compound and the other methoxy-substituted derivatives show poor photoluminescence from the solid state. HOMO/LUMO energy levels were determined by means of electrochemical and photophysical methods and were compared to those obtained by computational methods using B3LYP/6-31G(d) DFT calculations with a Polarisable Continuum Model (CPCM) for the solvent $\mathrm{CH}_{2} \mathrm{Cl}_{2}$. Good linear correlation was observed between calculated and experimentally measured values, and the correlations were used to estimate experimental HOMO/LUMO energy values of still non-synthesized heteroatom extended heteroacenes.
\end{abstract}

\section{Introduction}

Organic semiconductors gain remarkable interest due to their potential use in large-area, low-cost, light-weight electronic and optoelectronic materials, ${ }^{1}$ which are greatly needed for next generation smart cards, solar cells, and flexible lightning devices and displays. Many organic semiconductors are currently discussed as active layers in organic light emitting diodes (OLEDs), organic field-effect transistors (OFETs), or photovoltaic cells. ${ }^{2}$ Either polymers or small molecules are addressed in this field where the latter benefit from the fact of being homogeneous and well defined by means of molecular structure. Furthermore, small molecule semiconductors can be easily modified in their

\footnotetext{
${ }^{a}$ Laboratoire de Chimie Moléculaire et Thio-organique, CNRS UMR 6507, Normandie Univ, ENSICAEN \& UNICAEN, 6 Bvd Maréchal Juin, 14050 Caen, France. E-mail: bernhard.witulski@ensicaen.fr

${ }^{b}$ Chemistry, University of Southampton, Hants, SO17-1BJ, UK

$\dagger$ Electronic supplementary information (ESI) available: Detailed experimental and analytical data, additional cyclic voltammetry, DSC, TGA, photophysical and computational data, and ${ }^{1} \mathrm{H}$ and ${ }^{13} \mathrm{C}$ NMR spectra. See DOI: 10.1039/c6tc02009g
}

molecular structure and adjusted to the desired properties - and equally important - can be obtained in high purity. In this context acenes and their $\pi$-extended homologues are attractive materials (Fig. 1). For example, pentacene has set benchmarks for high hole mobilities of $2-5 \mathrm{~cm}^{2} \mathrm{~V}^{-1} \mathrm{~s}^{-1}$ in vacuum deposited OFETs. ${ }^{3}$

But the fact that pentacene is insoluble in organic solvents limits its use to vapour phase deposition techniques. Moreover, pentacene as well as other $\pi$-extended linear fused acenes have both high energy levels of the highest occupied molecular orbital (HOMO), and narrow band gaps. This makes them photodegradable, sensitive to air oxidation and results in performance decrease. ${ }^{4}$ These drawbacks render pentacene - as well as larger fused linear acenes - as less practical for further applications.

Appealing structural variants of linear fused acenes are ladder-type heteroacenes bearing thiophene, furan, pyrrole or phosphole units. ${ }^{5}$ In those heteroacenes, the heteroatom not only modifies the molecular structure but further alters electronic, photophysical, thermal, material and device properties. However, compared to the remarkable work devoted to the synthesis of 


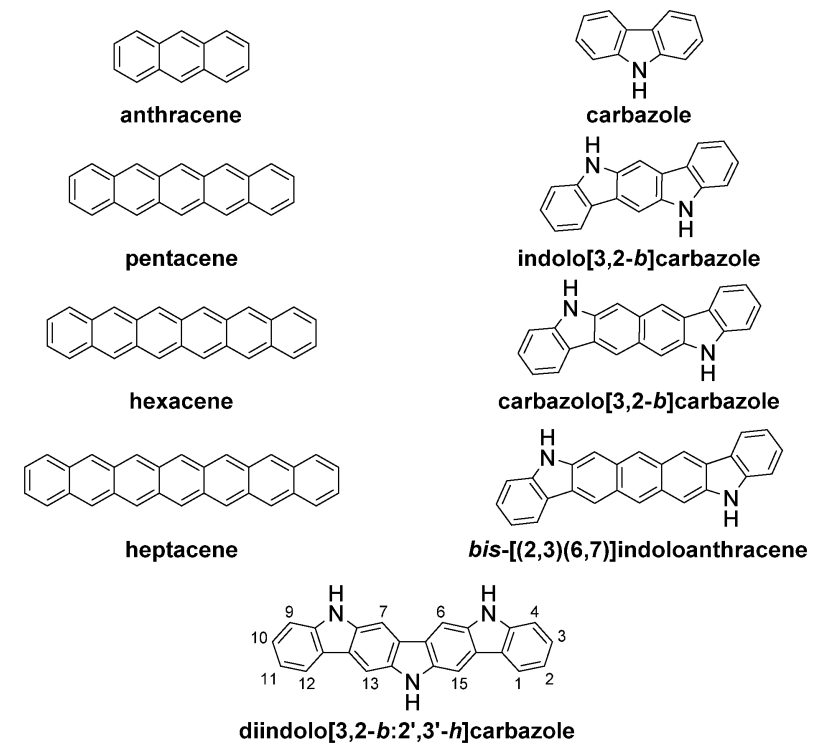

Fig. 1 Linear fused acenes and nitrogen containing linear fused heteroacenes.

pentacenes, examples focusing on the synthesis, molecular and material properties of linear fused heteroacenes are less well explored - particularly, with regard to the longer conjugated specimens approaching seven and more linear fused rings. ${ }^{6}$

Carbazole derivatives, specifically indolo $[3,2-b]$ carbazoles and diindolo $\left[3,2-b: 2^{\prime}, 3^{\prime}-h\right]$ carbazoles, that are isoelectronic structural variants of pentacene and heptacene respectively, have gained considerable interest as a promising class of hole-transporting semiconductors (Fig. 1). Their relatively low-lying HOMO levels and large band gaps make them interesting for applications in organic electronics.

Indolo $[3,2-b]$ carbazoles have a planar molecular structure and attachment of alkyl chains to the two nitrogen atoms allows the improvement of solubility, alters molecular self-assembly in films and solids, and defines material properties. ${ }^{7,8 a}$ Indolo[3,2- $\left.b\right]$ carbazoles showed great potential as active layers in OFETs, ${ }^{8}$ OLEDs, ${ }^{9}$ and in solution-processed bulk heterojunction solar cells. ${ }^{10} \pi$-Extended versions of indolocarbazoles, ${ }^{11}$ i.e. bis-indolonaphthalenes like the linear fused carbazolo[3,2- $b]$ carbazoles $^{12,13}$ and their angular fused core isomers - the carbazolo[1,2- $a$ carbazoles and carbazolo[4,3-c] carbazoles $^{13,14}$ - show promising features in OFETs, as well as hole transporting and light emitting material in phosphorescent OLEDs. ${ }^{14,15}$ The synthesis of $\pi$-enlarged versions of indolo[3,2- $b]$ carbazoles, the linear fused syn- and anti-bis-[(2,3)(6,7)]indoloanthracenes was reported. ${ }^{16}$ More recently, we described the synthesis, molecular and photophysical properties of the angular fused 7-membered ring heteroacene bis-[(1,2)(5,6)]indoloanthracene ${ }^{17 a}$ as well as the 9-ring angular fused biscarbazolo $\left[3,4-a: 3^{\prime}, 4^{\prime}-h\right]$ anthracene $^{17 b}$ and their use as the active layer of respectively highly sky-blue and white light emissive OLEDs.

Diindolo $\left[3,2-b: 2^{\prime}, 3^{\prime}-h\right]$ carbazoles having three carbazole units embedded in their molecular skeleton are the largest members of solely nitrogen containing linear fused heteroacenes being accessed so far. Chemistry and material application of the diindolo $\left[3,2-b: 2^{\prime}, 3^{\prime}-h\right]$ carbazole have been greatly pioneered by Leclerc who also disclosed potential applications in the fields of organic electronics. ${ }^{18-20}$ However, to the best of our knowledge only the parent system, the 1,15-dimethyl substituted and the 3,10-dichloro derivative, have been described. 1,15-dimethyldiindolo[3,2- $\left.b: 2^{\prime}, 3^{\prime}-h\right]$ carbazole was first obtained through a low-yielding non-regioselective Cadogan reaction. ${ }^{18}$ The parent compound as well as the dichloro derivative became available through a more straightforward synthetic approach utilizing a copper mediated Ullman coupling. ${ }^{19}$ Moreover, Yamamoto polymerization of 3,10-dichloro-diindolo[3,2- $\left.b: 2^{\prime}, 3^{\prime}-h\right]$ carbazole gave polymers with promising conductive as well as thermoelectric properties. $^{20}$

With only three described and characterized examples the chemistry of diindolo $\left[3,2-b: 2^{\prime}, 3^{\prime}-h\right]$ carbazoles remains an open field - particularly, because these heteroacenes provide an important class of materials for applications in organic electronics. The interest in extending linear fused indolocarbazoles to the more conjugated $\pi$-extended diindolo[3,2- $\left.b: 2^{\prime}, 3^{\prime}-h\right]$ carbazoles lies hereby not only in the thus reduced band gaps but also in the enhancement of charge transport properties due to efficient intermolecular $\pi-\pi$ overlap and electronic coupling. Furthermore, a well-adjusted substitution pattern on the diindolocarbazole scaffold might induce molecular self-assembly in the solid state and allow electronic fine tuning of HOMO/LUMO energy levels. Notably, the substitution pattern also influences the reorganization energy after hole-injection compared to the non-substituted compound and thus will alter intrinsic charge-carrier mobilities of materials. ${ }^{21}$

In this paper we provide an experimental and computational study on a set of methoxy-substituted diindolo[3,2- $\left.b: 2^{\prime}, 3^{\prime}-h\right]-$ carbazoles, their thermal, electrochemical, as well as photophysical properties including solution and solid states.

\section{Results and discussion}

\section{Synthesis}

For the construction of the diindolo[3,2- $\left.b: 2^{\prime}, 3^{\prime}-h\right]$ carbazole scaffold a building block strategy based on Suzuki-Miyaura ${ }^{22}$ reactions with the readily available carbazole 1 and a set of aryl and heteroaryl boronic acids (2-9) was chosen (Table 1). Our synthetic strategy proceeds with regioselective twofold Cadogan reactions, ${ }^{23}$ and with $\mathrm{N}$-alkylations that provide the necessary solubility and processability of the final products. Notably, all follow-up transformations of carbazole 1 (Suzuki coupling, Cadogan reaction, and $N$-alkylation) are twofold securing a rapid and stepeconomic synthesis. $^{24}$

The Suzuki-Miyaura cross-coupling reaction of di-bromodinitrocarbazole 1 with various aryl and heteroaryl boronic acids (2-9) was either performed by conventional heating (Schlenk tube in oil bath) or by microwave heating. For cross-couplings under conventional heating $5 \mathrm{~mol} \% \mathrm{Pd}\left(\mathrm{PPh}_{3}\right)_{4}$ as a catalyst in dry THF and cesium fluoride as base were used. However, under these conditions the coupling reactions needed 2 days for completion. The reaction time for the twofold Suzuki-Miyaura couplings was 
Table 1 Products and respective yields of isolated compounds obtained by the sequence of twofold Suzuki, Cadogan and $\mathrm{N}$-alkylation reactions starting from carbazole 1

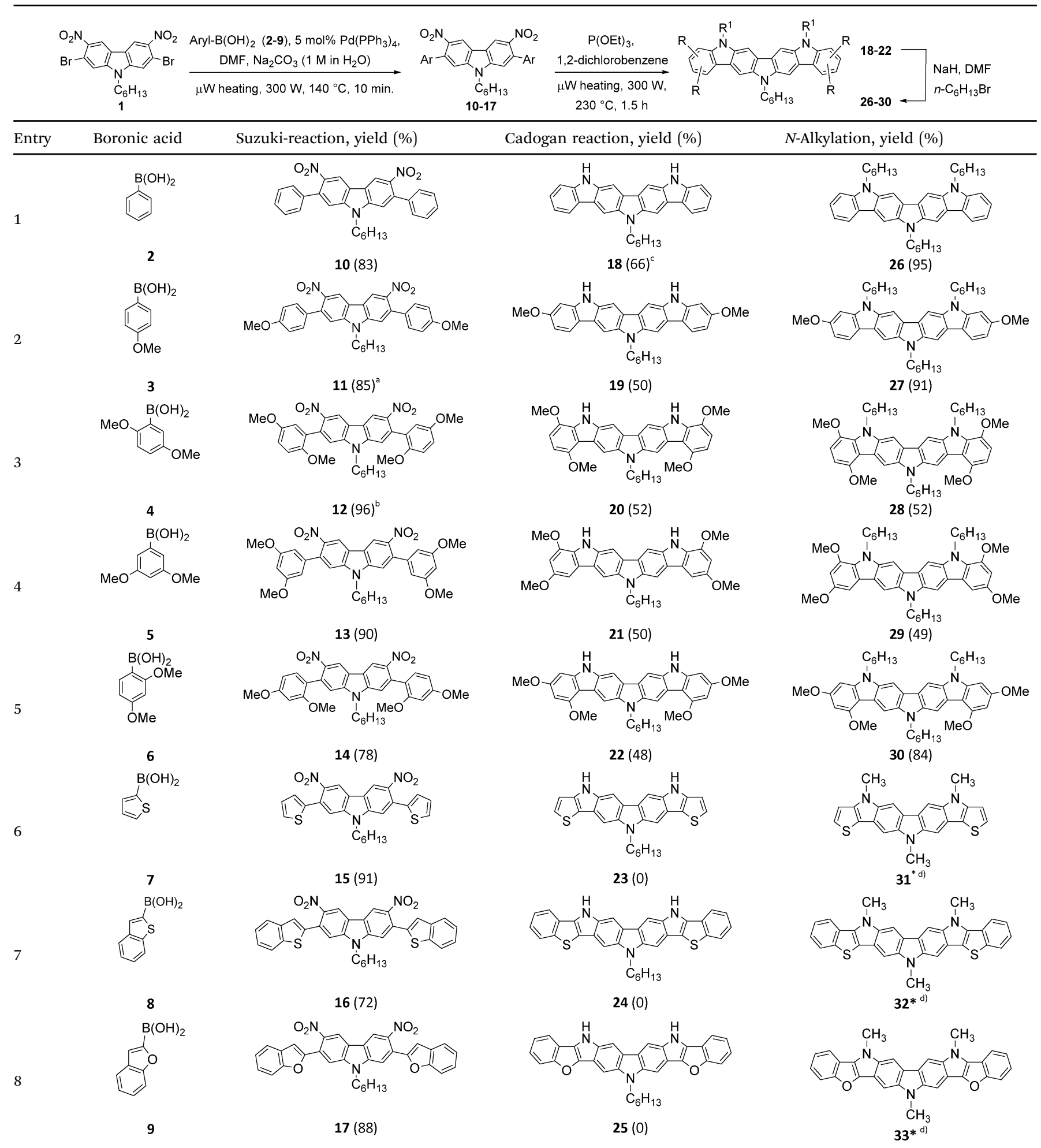

${ }^{a} 87 \%$ isolated yield with conventional heating ( $70{ }^{\circ} \mathrm{C}, 2$ days). ${ }^{b}$ Synthesized by conventional heating. ${ }^{c}$ A yield of $25 \%$ was obtained by conventional heating $\left(230^{\circ} \mathrm{C}, 24 \mathrm{~h}\right) .{ }^{d}$ Molecule investigated by computational methods only, see text.

significantly reduced to 10 minutes, when the reactions were performed under microwave heating $\left(300 \mathrm{~W}, 140{ }^{\circ} \mathrm{C}\right)$. Here, best reactions conditions involved the use of $5 \mathrm{~mol} \% \mathrm{Pd}\left(\mathrm{PPh}_{3}\right)_{4}$ in
DMF/water and $\mathrm{Na}_{2} \mathrm{CO}_{3}$. The microwave accelerated Suzuki reactions gave the cross-coupling products $\mathbf{1 0 - 1 7}$ respectively in yields of $72-96 \%$ (Table 1 ). The coupling reactions were 
equally effective by using either aryl 2-6 or heteroaryl 7-9 boronic acids. Next, the twofold Cadogan reaction for the assembly of the diindolo $\left[3,2-b: 2^{\prime}, 3^{\prime}-h\right]$ carbazole scaffold was investigated. Although the Cadogan reaction is a versatile reaction for the synthesis of carbazoles, $^{23,25}$ its application for the synthesis of diindolocarbazoles has been reported to be non-regioselective and lowyielding. ${ }^{18}$ Indeed, when the dinitro compound 10 was heated to $230{ }^{\circ} \mathrm{C}$ in triethylphosphite/1,2-dichlorobenzene the reaction proceeded very slowly over a period of $24 \mathrm{~h}$ to give product $18 \mathrm{in}$ $25 \%$ yield. Other variants of the Cadogan reaction, including the use of $\mathrm{P}(\mathrm{OEt})_{3}$ as solvent, $\mathrm{PPh}_{3} /$ dichlorobenzene, ${ }^{26}$ or related oxygen transfer reactions mediated through a molybdenum catalyst, ${ }^{27}$ were even less effective. Gratifyingly, when the twofold Cadogan reaction was performed under microwave heating $\left(300 \mathrm{~W}, 230{ }^{\circ} \mathrm{C}\right)$ in $\mathrm{P}(\mathrm{OEt})_{3} / 1,2$-dichlorobenzene, ${ }^{28}$ the diindolocarbazole 18 was obtained within $1.5 \mathrm{~h}$ in $66 \%$ yield as a yellow powder. The microwave accelerated Cadogan reaction was also effective to give the methoxy-substituted diindolocarbazoles 19-22 respectively via a twofold ring-closure reaction in yields of $48-52 \%$. Unexpectedly, neither a reaction under conventional heating nor the microwave accelerated version delivered the heteroacenes 23-25. For these cases, a complete conversion of the corresponding dinitrocompounds 15-17 was observed (as indicated by TLC), but we were unable to isolate any diindolocarbazole products 23-25 most probably due to their insolubility.

Finally, a double $N$-alkylation of the Cadogan products 18-22 with $n$-hexylbromide in NaH/DMF made the targeted diindolocarbazoles 26-30 available in high yield (49-95\%). The thus obtained diindolo[3,2-b:2', $\left.3^{\prime}-h\right]$ carbazoles, the parent nonsubstituted compound 26 and the four methoxy-substituted variants 27-30, were soluble in organic solvents such as chloroform, dichloromethane, chlorobenzene or hot toluene. Furthermore, they could be purified by simple flash chromatography on silica gel. The molecular structures of all new diindolo[3,2$\left.b: 2^{\prime}, 3^{\prime}-h\right]$ carbazoles 26-30 were confirmed by ${ }^{1} \mathrm{H}$ and ${ }^{13} \mathrm{C}$ NMR spectroscopy and analytical methods. They are described in detail in the ESI. $\dagger$

The unexpected complications encountered with reactions leading to the heteroacenes 23-25 were investigated in more detail. Further support that the lack of efficiency of microwave accelerated Cadogan reactions to give the heteroacenes 23-25 was based on difficulties encountered by product insolubility rather than by intrinsic reactivity with heteroaromatic moieties ${ }^{29}$ was gained with the nitro compounds 34-36 (Scheme 1).

The microwave accelerated Cadogan reaction with the nitrocompounds 34-36 having either a thiophene, benzothiophene or benzofurane unit gave under otherwise identical reaction conditions the mixed heteroatom containing heteroacenes $37-39$ in high yields of, respectively, $63 \%, 86 \%$ and $90 \%$. The products where thereafter converted to the $\mathrm{N}$-alkylated derivatives 40-42 facilitating purification and characterisation by analytical means.

Finally, the here developed synthesis of diindolo[3,2- $\left.b: 2^{\prime}, 3^{\prime}-h\right]$ carbazoles using a consecutive sequence of twofold Suzuki, Cadogan and $N$-alkylation reactions is remarkably short and efficient. With only 3 steps from readily available carbazole $\mathbf{1}$,
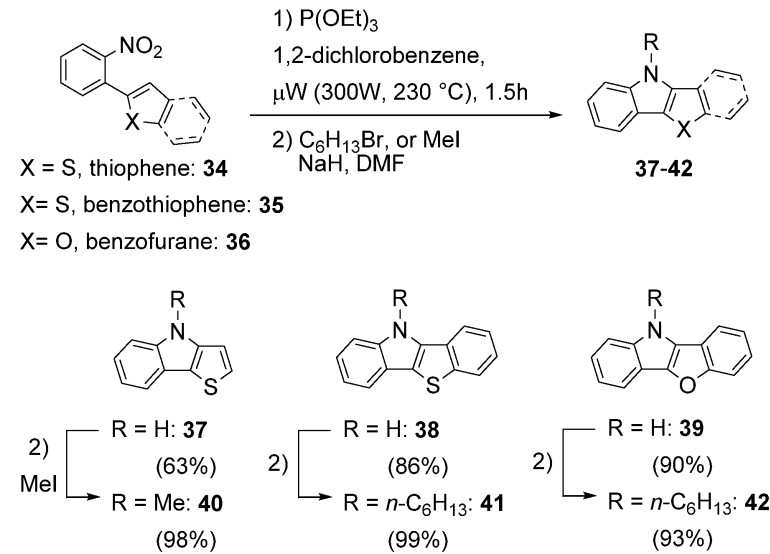

Scheme 1 Microwave accelerated Cadogan reaction for the synthesis of mixed heteroatom containing heteroacenes.

and with an overall yield of $52 \%$ for the parent diindolocarbazole 26, this synthesis is - regarding step-count and overall yield - more efficient than previously reported syntheses of this important class of organic semiconductors.

\section{Thermal properties}

The thermal properties of the diindolocarbazoles 26-30 were investigated by differential scanning calorimetry (DSC) and thermogravimetric analysis (TGA). DSC measurements revealed relatively sharp melting peaks for the heteroacenes $26,27,28$, and 30 with maxima at $168{ }^{\circ} \mathrm{C}, 193{ }^{\circ} \mathrm{C}, 163{ }^{\circ} \mathrm{C}$, and $166{ }^{\circ} \mathrm{C}$, respectively, as well as matching crystallisation peaks for both the first and the second heating-cooling cycles. Notably, the DSC of compounds 26 and 27 also shows minor phase transitions that are probably based on "chain-melting" processes. Additionally, TGA demonstrated excellent thermal stabilities up to $400-450{ }^{\circ} \mathrm{C}$ (for DSC and TGA, see $\mathrm{ESI} \dagger$ ).

\section{Photophysical properties}

UV-vis absorption and photoluminescence spectra of 26-30 in solution $\left(\mathrm{CH}_{2} \mathrm{Cl}_{2}\right)$ as well as solids were recorded, and their optical properties are summarized in Table 2.

The UV-vis absorption spectra recorded in $\mathrm{CH}_{2} \mathrm{Cl}_{2}$ solutions display characteristic low-energy transitions in the 437-476 nm region that are individually accompanied by vibronic satellites and reflect transitions in the $S_{1}$ excited state. Accordingly, the much stronger absorption band in the $378-384 \mathrm{~nm}$ region is assigned to the $S_{0} \rightarrow S_{2}$ transition. Wavelength and intensities of the absorption spectra are in good agreement with previous theoretical investigations of the non-substituted diindolo[3,2$\left.b: 2^{\prime}, 3^{\prime}-h\right]$ carbazole. ${ }^{30} \mathrm{UV}$-vis absorption and photoluminescence spectra of the parent diindolocarbazole 26 and the three tetramethoxy-substituted derivatives 28, 29, and 30 having each a different substitution pattern are shown in Fig. 2 (the complete set of absorption, emission and excitation spectra for 26-30 can be found in the ESI $\dagger$ ).

Notably, UV-vis absorption as well as photoluminescence properties are significantly influenced by the number of methoxy substituents and particularly by their specific substitution 
Table 2 Photophysical data of diindolocarbazoles $26-30$ in $\mathrm{CH}_{2} \mathrm{Cl}_{2}$ and crystals

\begin{tabular}{|c|c|c|c|c|c|c|}
\hline Comp. & $\begin{array}{l}{ }^{\mathrm{abs}} \lambda_{\max }{ }^{a} \\
\mathrm{CH}_{2} \mathrm{Cl}_{2}(\mathrm{~nm})\end{array}$ & $\begin{array}{l}{ }^{\mathrm{em}} \lambda_{\max }{ }^{b} \\
\mathrm{CH}_{2} \mathrm{Cl}_{2}(\mathrm{~nm})\end{array}$ & $\begin{array}{l}{ }^{\mathrm{em}} \lambda_{\max } \\
\text { solid (nm) }\end{array}$ & $\begin{array}{l}\Phi_{\mathrm{F}}^{c} \\
\mathrm{CH}_{2} \mathrm{Cl}_{2}\end{array}$ & $\begin{array}{l}\Phi_{\mathrm{F}} \\
\text { solid }\end{array}$ & $\begin{array}{l}E_{\mathrm{g}}{ }^{d} \\
(\mathrm{eV})\end{array}$ \\
\hline \multirow[t]{2}{*}{26} & 465 & 474 & $-^{e}$ & 0.22 & $-^{e}$ & 2.59 \\
\hline & 439 & 509 & & & & \\
\hline \multirow[t]{2}{*}{27} & 449 & 460 & 506 & 0.26 & 0.02 & 2.68 \\
\hline & 425 & 490 & & & & \\
\hline \multirow[t]{2}{*}{28} & 458 & 467 & 562 & 0.22 & 0.14 & 2.62 \\
\hline & 433 & 498 & $606^{f}$ & & & \\
\hline \multirow[t]{2}{*}{29} & 476 & 487 & 528 & 0.20 & 0.02 & 2.53 \\
\hline & 447 & 520 & $575^{f}$ & & & \\
\hline \multirow[t]{2}{*}{30} & 437 & 447 & $-^{e}$ & 0.27 & $-^{e}$ & 2.76 \\
\hline & 415 & 476 & & & & \\
\hline
\end{tabular}

${ }^{a}$ In $\mathrm{CH}_{2} \mathrm{Cl}_{2} \cdot{ }^{b} 10^{-6} \mathrm{M}$ in $\mathrm{CH}_{2} \mathrm{Cl}_{2} \cdot{ }^{c}$ Absolute quantum yield measured with an integration sphere, a $10^{-6} \mathrm{M}$ solution of the compound in $\mathrm{CH}_{2} \mathrm{Cl}_{2}$ was purged with argon prior to measurement. ${ }^{d}$ Optical band gap energy determined from the $\lambda_{\text {onset }}$ value of the long-wavelength absorption band. ${ }^{e}$ Non-emissive. ${ }^{f}$ Shoulder.

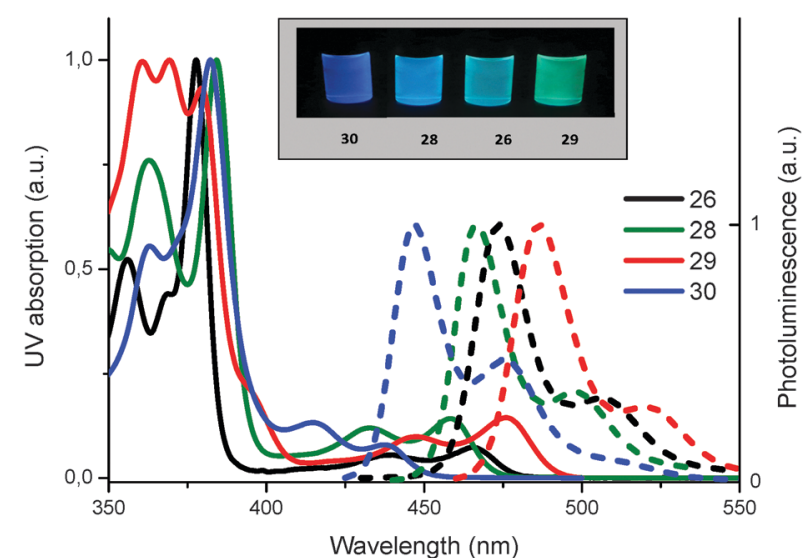

Fig. 2 Normalized UV-vis absorption (solid lines) and PL spectra (dashed lines) of the diindolocarbazoles 26 (black), 28 (green), 29 (red) and $\mathbf{3 0}$ (blue) in $\mathrm{CH}_{2} \mathrm{Cl}_{2}\left(10^{-6} \mathrm{M}\right)$. Inset: solution of diindolocarbazoles $30,28,26$ and 29 in $\mathrm{CH}_{2} \mathrm{Cl}_{2}$ under UV light.

pattern on the diindolo $\left[3,2-b: 2^{\prime}, 3^{\prime}-h\right]$ carbazole framework. The absorption band corresponding to the $\mathrm{S}_{0} \rightarrow \mathrm{S}_{1}$ transition is blue-shifted for the 3,10-dimethoxy-27 ( ${ }^{\text {abs }} \lambda_{\max }=449 \mathrm{~nm}$ ), as well as for the 1,4,9,12-tetramethoxy-28 ( ${ }^{\text {abs }} \lambda_{\max }=458 \mathrm{~nm}$ ) and the 1,3,10,12-tetramethoxy-30 ( ${ }^{\text {abs }} \lambda_{\max }=437 \mathrm{~nm}$ ) derivative, whereas the 2,4,9,11-tetramethoxy isomer $29\left({ }^{\mathrm{abs}} \lambda_{\max }=476 \mathrm{~nm}\right)$ is significantly red-shifted, with respect to the parent nonsubstituted compound 26 ( ${ }^{\text {abs }} \lambda_{\max }=465 \mathrm{~nm}$, Table 2 and Fig. 2$)$. The photoluminescence spectra of this set of diindolo[3,2-b:2' $\left.{ }^{\prime} 3^{\prime}-h\right]$ carbazoles follow the same trend with emission bands at $\mathrm{em}_{\lambda_{\max }}=460,467$, and $447 \mathrm{~nm}$ for the hypsochromic shifted spectra of diindolocarbazoles $\mathbf{2 7}, \mathbf{2 8}$, and $\mathbf{3 0}$, respectively, as well as for the bathochromic shifted photoluminescence spectra of diindolocarbazole $29\left({ }^{\mathrm{em}} \lambda_{\max }=487 \mathrm{~nm}\right)$ with respect to the photoluminescence spectra of the non-substituted 26 $\left({ }^{\mathrm{em}} \lambda_{\max }=474 \mathrm{~nm}\right)$. Such a spectroscopic series underlines that the methoxy-substituents might allow the fine-tuning of optoelectronic properties. The emission spectra of the diindolo[3,2$\left.b: 2^{\prime}, 3^{\prime}-h\right]$ carbazoles 26-30 show all very small Stokes shifts of
9-11 nm (404-474 $\left.\mathrm{cm}^{-1}\right)$ reflecting the expected rigidity of these planar 7-ring linear fused heteroacenes. Furthermore, the shape of the low-energy absorption bands and the corresponding fluorescence emission bands mirror each other. Such low Stokes shifts and mirror-image profiles are due to similar geometries of ground and first excited states, as well as a similar nature of the absorbing and emitting electronic levels.

Photoluminescence quantum yields of diindolocarbazoles 26-30 were measured with the help of an integration sphere in argon purged dichloromethane solutions as well as solids (Table 2). Quantum yields for this set of heteroacenes in solution are equal with values between $\phi_{\mathrm{F}}=0.2$ and 0.3 and no trend with respect to the number and substitution pattern of methoxy groups was revealed. Quantum yields of solid state photoluminescence from 26 to 30 are rather low compared to those in solution. This is most likely due to an aggregate caused quenching (ACQ) that is often accompanied by close face-to-face or $\pi-\pi$ stacking interactions of $\pi$-extended aromatic or heteroaromatic compounds in the solid state. ${ }^{31}$ However, such a $\pi-\pi$ molecular packing motif can lead to the formation of excimer-type emission, ${ }^{32}$ that is recognized by a significantly red-shifted photoluminescence emission with respect to the one in solution.

Notably, bright yellow fluorescence $\left({ }^{\mathrm{em}} \lambda_{\max }=562 \mathrm{~nm}\right)$ with a quantum yield of $\phi_{\mathrm{F}}=0.14$ was observed for the solid state photoluminescence of the $N, N, N$-tri- $n$-hexyl-1,4,9,12-tetramethoxy diindolo[3,2-b:2' $\left.3^{\prime}-h\right]$ carbazole 28 (Table 2 and Fig. 3). The corresponding photoluminescence spectra of solid 28 is distinctly red-shifted (about $95 \mathrm{~nm}$ compared to the emission spectra in solution) and broadened with respect to the one in solution. This points to a specific aggregate formation of $\mathbf{2 8}$ in the solid state that favours excimer-type light emission.

The bright photoluminescence of solid 28 and its high efficiency is remarkable, as the other diindolocarbazoles in this series exhibit only poor solid state photoluminescence properties (Table 2). $N$-Alkyl side chains and the methoxy-group substitution pattern of the diindolocarbazole 28 seem to be critical in order to control supramolecular aggregation in such a way that segregation between heteroaromatic scaffolds

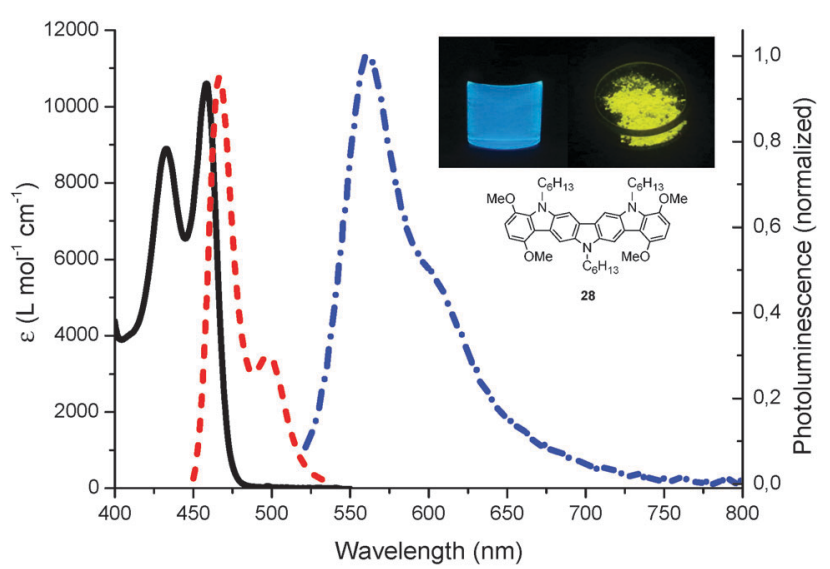

Fig. 3 UV-vis absorption [black line] and PL spectra of diindolocarbazole 28 in solution $\left(10^{-6} \mathrm{M}\right.$ in $\left.\mathrm{CH}_{2} \mathrm{Cl}_{2}\right)$ [dashed red line] and $\mathrm{PL}$ of solid [blue dashed-dotted line]. Inset: solution of 28 in $\mathrm{CH}_{2} \mathrm{Cl}_{2}$ and solid under UV-light. 
and alkyl chains favours $\pi-\pi$ interaction that induce effective excimer-type formation in the solid without dominating ACQ effects.

A red-shifted solid state photoluminescence is also found for the methoxy-substituted diindolocarbazoles 27 and 29, albeit for these examples the red-shift is less pronounced (about $40 \mathrm{~nm}$ with respect to the photoluminescence in solution) and accompanied by a much less intense photoluminescence efficiency ( $\phi_{\mathrm{F}} \sim 0.02$ for 27 and 29, Table 2). Furthermore, the parent compound 26 and the 1,3,10,12-tetramethoxy-substituted derivative $\mathbf{3 0}$ are non-emissive in the solid state (for the full set of solid state photoluminescence spectra, see the ESI $\dagger$ ).

Optical band gap energies $\left(E_{\mathrm{g}}\right)$ of the parent diindolo[3,2$\left.b: 2^{\prime}, 3^{\prime}-h\right]$ carbazole 26 and the four methoxy-substituted variants 27-30 were estimated from the onset values ( $\left.\lambda_{\text {onset }}\right)$ of the solution absorption spectra and are listed in Table 2.

\section{Electrochemical properties}

The electrochemical properties of diindolo[3,2- $\left.b: 2^{\prime}, 3^{\prime}-h\right]$ carbazoles 26-30 were investigated by cyclic voltammetry and the results are displayed in Table 3. Cyclic voltammetry experiments were carried out with a scan rate of $100 \mathrm{mV} \mathrm{s}{ }^{-1}$, with $\mathrm{Bu}_{4} \mathrm{NPF}_{6}\left(0.1 \mathrm{M}\right.$ in $\left.\mathrm{CH}_{2} \mathrm{Cl}_{2}\right)$ as the electrolyte solution, and with $\mathrm{Fc}^{*} / \mathrm{Fc}^{*^{+}}(-0.13 \mathrm{~V} v \mathrm{~s} \text {. SCE })^{33}$ as the internal standard ( $\mathrm{Fc}^{*}$ : decamethyl ferrocene). Within the solvent/electrolyte window the parent non-substituted compound 26 showed two oxidation potentials, whereas the methoxy group bearing variants $\mathbf{2 7 - 3 0}$ respectively compiled more than three oxidation levels each.

The cyclic voltammogram of the 1,4,9,12-tetramethoxy diindolo$\left[3,2-b: 2^{\prime}, 3^{\prime}-h\right]$ carbazole 28 is displayed in Fig. 4 as a representative example (for the full set of cyclic voltammograms, see the ESI $\dagger$ ). The first oxidation is for all investigated diindolocarbazoles fully reversible, with quasi-reversible oxidations for the second and third potentials. In comparison with the parent nonsubstituted diindolocarbazole $\mathbf{2 6}$, the first oxidation potential decreased with the number of methoxy-group substituents increased. For example for the series 26, 27, and 28 having none, two and four methoxy substituents, respectively, the halfwave potential $E_{1 / 2}$ decreases in the order $0.47,0.45$, and $0.39 \mathrm{~V}$. In these cases the methoxy groups introduced onto the diindolocarbazole framework simply act as strong electron-donating groups. However, distinguished contributions are caused by the substitution pattern as revealed by a more detailed analysis of the corresponding HOMO/LUMO energy levels; especially for the set 28, 29, and 30 having all four methoxy groups in different positions.

Table 3 Electrochemical data of compounds $26-30^{a}$

\begin{tabular}{lllll}
\hline Comp. & $E_{1 / 2}{ }^{b}(\mathrm{~V})$ & ${ }^{\mathrm{ox}} E_{\text {onset }}(\mathrm{V})$ & $E_{\text {HOMO }}(\mathrm{eV})$ & $E_{\text {LUMO }}(\mathrm{eV})$ \\
\hline $\mathbf{2 6}$ & $0.47,1.05$ & 0.42 & -5.06 & -2.47 \\
$\mathbf{2 7}$ & $0.45,0.99,1.12$ & 0.40 & -5.04 & -2.36 \\
$\mathbf{2 8}$ & $0.39,0.73,0.84$ & 0.32 & -4.96 & -2.34 \\
$\mathbf{2 9}$ & $0.33,0.66,0.86$ & 0.28 & -4.92 & -2.39 \\
$\mathbf{3 0}$ & $0.43,0.85,1.00$ & 0.36 & -5.00 & -2.24
\end{tabular}

${ }^{a}$ Recorded in $\mathrm{CH}_{2} \mathrm{Cl}_{2} / 0.1 \mathrm{M} n-\mathrm{Bu}_{4} \mathrm{PF}_{6}$ at room temperature vs. SCE.

${ }^{b}$ Values calibrated against $\mathrm{Fc}^{*^{+}} / \mathrm{Fc}^{*}(-0.13 \mathrm{~V})$.

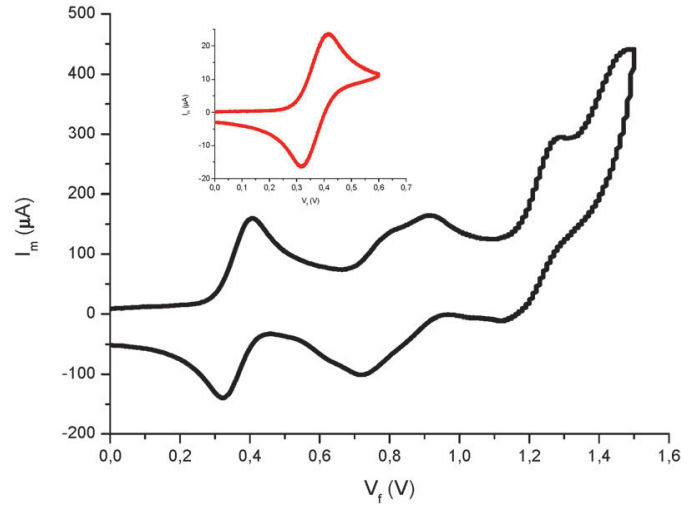

Fig. 4 Cyclic voltammetry of 1,4,9,12-tetramethoxy diindolo[3,2- $\left.b: 2^{\prime}, 3^{\prime}-h\right]$ carbazole $28\left(10^{-3} \mathrm{M}\right.$ in $\left.\mathrm{CH}_{2} \mathrm{Cl}_{2} / 0.1 \mathrm{M} n-\mathrm{Bu}_{4} \mathrm{NPF}_{6}\right)$ at room temperature. Scan rate $100 \mathrm{mV} \mathrm{s}^{-1}$, recorded vs. SCE. Inset: first oxidation potential.

From the onset of the first oxidation half-wave $\left({ }^{\mathrm{ox}} E_{\text {onset }}\right)$ the HOMO energy level for the diindolocarbazoles 26-30 was estimated using $E_{\text {номо }}=-\left({ }^{\mathrm{ox}} E_{\text {onset }}\right.$, vs. $\left.\mathrm{Fc} / \mathrm{Fc}^{+}+5.10\right)(\mathrm{eV})$ for measurements in dichloromethane solution with $0.1 \mathrm{M} \mathrm{Bu}_{4} \mathrm{NPF}_{6}$ as the supporting electrolyte. ${ }^{34}$ The half-wave potential for the $\mathrm{Fc} / \mathrm{Fc}^{+}$redox-couple was set to $E_{1 / 2}=0.46$ for calibration purpose. ${ }^{33}$ We chose here $-5.10 \mathrm{eV}$ as the formal potential of the $\mathrm{Fc} / \mathrm{Fc}^{+}$redox couple in the Fermi scale and not the quite often used value of $-4.8 \mathrm{eV}$ for $0.0 \mathrm{~V}$ versus $\mathrm{Fc} / \mathrm{Fc}^{+}$based on a recent discussion by Bazan et al. $^{34}$ The former calibration scale of $-5.10 \mathrm{eV}$ is based on several empirically obtained electrochemical data and reflects best the stability of the redox species involved. The HOMO energy level for the parent non-substituted diindolo[3,2- $\left.b: 2^{\prime}, 3^{\prime}-h\right]$ carbazole 26 was thus estimated to $E_{\text {Hомо }}=-5.06 \mathrm{eV}$. For the 3,10-dimethoxy27 derivative the HOMO energy level was found to be $E_{\mathrm{HOMO}}=$ $-5.04 \mathrm{eV}$, and the three tetramethoxy derivatives 28, 29, and 30 revealed energy levels of $E_{\text {Hомо }}=-4.96,-4.92$, and $-5.00 \mathrm{eV}$ respectively. These results furthermore underline the strong electron donating properties of methoxy substituents in the diindolo[3,2- $\left.b: 2^{\prime}, 3^{\prime}-h\right]$ carbazole framework.

The HOMO energy of the parent non-substituted diindolo$\left[3,2-b: 2^{\prime}, 3^{\prime}-h\right]$ carbazole $26\left(E_{\text {номо }}=-5.06 \mathrm{eV}\right)$ is slightly increased in comparison to the previously reported HOMO levels of $N, N$-dimethylindolo[3,2- $b]$ carbazole $\left[E_{\mathrm{HOMO}}=-5.12 \mathrm{eV}\right]$ and $N$-methylcarbazole $\left[E_{\text {Номо }}=-5.64 \mathrm{eV}\right] . \neq$ The increase of the extension of $\pi$-conjugation from $N$-methylcarbazole to $N, N$-dimethylindolo[3,2- $b]$ carbazole and to $N, N, N$-trihexyl-diindolo$\left[3,2-b: 2^{\prime}, 3^{\prime}-h\right]$ carbazole 26 correlates well with the observed moderate increase of HOMO energies.

Notably, the low-energy HOMO levels of $-5.06 \mathrm{eV}$ to $-4.92 \mathrm{eV}$ found for the diindolo[3,2-b:2', $\left.3^{\prime}-h\right]$ carbazoles 26-30 make them potentially suitable for hole injection and hole transport in a thinfilm based electronic device - and should guarantee a reasonable long-term stability.

$\ddagger$ HOMO energies of $N, N$-dimethylindolo[3,2- $b]$ carbazole and $N$-methylcarbazole were recalculated from data reported in ref. $8 \mathrm{a}$ with respect to the here used formal potential of the $\mathrm{Fc} / \mathrm{Fc}^{+}$redox couple in the Fermi scale. 
The energy level of the lowest unoccupied molecular orbital (LUMO) was calculated by adding the value of the optical band gap ( ${ }^{\mathrm{opt}} E_{\mathrm{g}}$ in Table 2) taken from the onset of the longwavelength absorption band of the UV-vis absorption spectra to the HOMO energy level with $E_{\mathrm{LUMO}}=E_{\mathrm{HOMO}}+{ }^{\mathrm{opt}} E_{\mathrm{g}}$. The experimentally established HOMO/LUMO energy levels of the here synthesized and investigated diindolocarbazoles $\mathbf{2 6 - 3 0}$ are listed in Table 3.

\section{Theoretical calculations}

With the aim of gaining further insight into how the substitution degree and pattern influence the HOMO energy level and the HOMO-LUMO gap of diindolo[ $\left[3,2-b: 2^{\prime}, 3^{\prime}-h\right]$ carbazoles, and of establishing a method to predict these parameters for compounds not synthesised, theoretical calculations were carried out. Calculations were performed using methyl- instead of $n$-hexyl groups on the nitrogen atoms for reasons of simplicity (the computation generated diindolo[3,2-b:2', $\left.3^{\prime}-h\right]$ carbazoles are labelled as $26^{*}, 27^{*}, 28^{*}, 29^{*}$, and $30^{*}$ to distinguish them from the synthesised corresponding counterparts bearing $N$ - $n$-hexyl groups). We applied density function theory (DFT) using the hybrid-generalized gradient approximation functional ${ }^{B} 3 L_{Y P}{ }^{35}$ with the split-valence polarized basis set size $6-31 \mathrm{G}(\mathrm{d})^{36}$ and a Conductor-like Polarisable Continuum Model (CPCM) ${ }^{37}$ to allow for the solvent $\left(\mathrm{CH}_{2} \mathrm{Cl}_{2}\right)$ used in electrochemical and UV measurements, as implemented in Gaussian-09 (rev. D.01). ${ }^{38}$ Several studies have shown that calculated HOMO-LUMO band gaps are linearly correlated with observed band gaps, at least within a series of related compounds, and B3LYP/6-31G(d) performs well. ${ }^{39}$ The values we obtain for HOMO and LUMO levels of $26^{*}-30^{*}$, and consequent energy gaps are given in Table 4 . Fig. 5 shows the comparison of empirically determined HOMO/ LUMO energy levels via a combination of electrochemical and optical measurements, and calculated ones obtained from the B3LYP/6-31G(d) DFT calculations. We observe a reasonable linear correlation (Fig. 6) between the observed optical band gap (Table 2) and HOMO-LUMO separation (Table 4), and between the 1st oxidation potential (Table 3) and the HOMO energy level (Table 4).

The molecular orbitals for the parent diindolocarbazole $26^{*}$, the 3,10-dimethoxy-2 $7^{*}$ and the three tetra-methoxy derivatives $28^{*}-30^{*}$ are displayed in Fig. 7. The geometry of both the HOMO and the LUMO of the methoxy substituted compounds are very similar

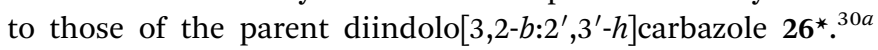

Table 4 Calculated HOMO, LUMO and band-gap for compounds $26 *-30{ }^{a}$

\begin{tabular}{llll}
\hline Comp. & HOMO $(\mathrm{eV})$ & LUMO $(\mathrm{eV})$ & Band gap $(\mathrm{eV})$ \\
\hline $\mathbf{2 6}^{*}$ & -4.690 & -1.351 & 3.339 \\
$\mathbf{2 7}^{*}$ & -4.663 & -1.227 & 3.437 \\
$\mathbf{2 8}^{*}$ & -4.535 & -1.172 & 3.363 \\
$\mathbf{2 9}^{*}$ & -4.497 & -1.278 & 3.220 \\
$\mathbf{3 0}^{*}$ & -4.593 & -1.060 & 5.533
\end{tabular}

${ }^{a}$ All energies were calculated using the Gaussian 09 rev D.01 program using the B3LYP functional with 6-31G(d) basis set and a CPCM solvent model for $\mathrm{CH}_{2} \mathrm{Cl}_{2}$.

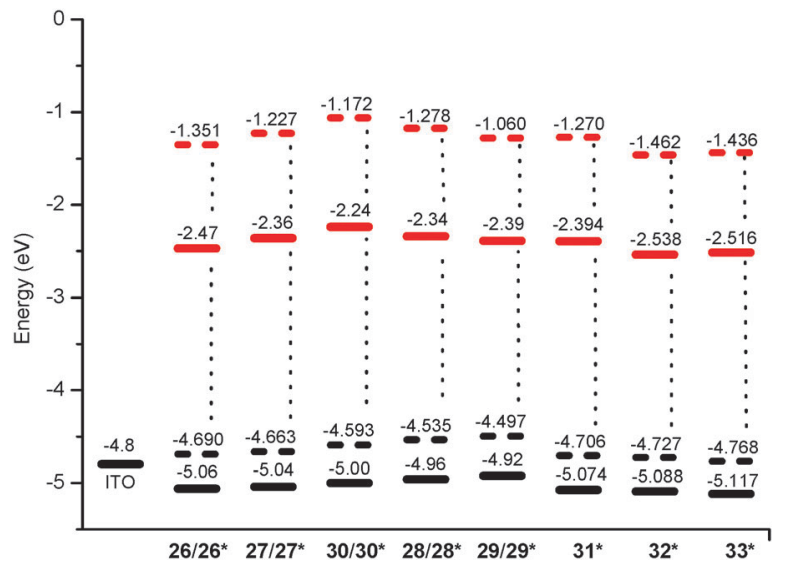

Fig. 5 Experimentally obtained HOMO/LUMO energies (solid lines) for 26-29 and estimated experimental values for $31^{*}-33^{*}$, as well as calculated (dashed lines) HOMO/LUMO energy levels of the heteroacenes 26*-33*. Calculation level DFT B3LYP/6-31G(d) in $\mathrm{CH}_{2} \mathrm{Cl}_{2}$.
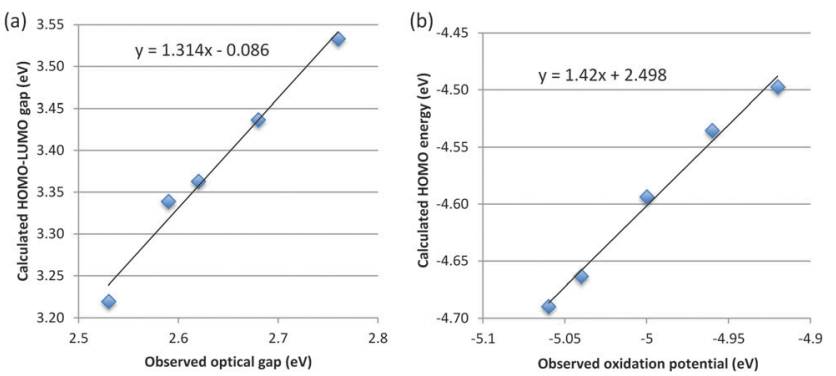

Fig. 6 (a) Correlation between calculated and observed band gaps. (b) Correlation between calculated and observed HOMO levels.

The coefficients of the HOMOs are mainly localized on the middle carbazole moiety, with smaller contributions from the two peripheral carbazole units. The changes in HOMO and LUMO levels are roughly consistent with methoxy substitution on carbons with a high orbital coefficient for that orbital increasing their energy. For the HOMO there are 0 methoxy substitutions on high coefficient carbons for $26 / 26^{*}, 27 / 27^{*}$ and $30 / 30^{*}$; 2 for $28 / 28^{*}$ and 4 for $29 / 29^{*}$, and for LUMO 0 for $26 / 26^{*}, 2$ for $27 / 27^{*}, 28 / 28^{*}$, and $29 / 29^{*}, 4$ for $30 / 30^{*}$. Notably, the HOMO/LUMO energy level changes do not change in the same direction, for example from $29 / 29^{*}$ to $30 / 30^{*}$ the HOMO increases and the LUMO decreases in energy (Fig. 5).

The good correlation observed between experimental and calculated HOMO and band-gap values (Fig. 6) was used to estimate the experimental values for the HOMO, the LUMO and band-gap we would expect to observe for molecules $31^{*}-33^{*}$ for which the current synthetic method failed (Table 5 and Fig. 5).

The expected experimental HOMO energies for heteroacenes $31^{*}-33^{*}$ are significantly lower than those for the experimentally investigated diindolocarbazoles 26-30 indicating that the formal placement of heteroatoms into the $\pi$-perimeter of an diindolocarbazole framework will not only lead to an extended molecular surface but also to more stable semiconductors 

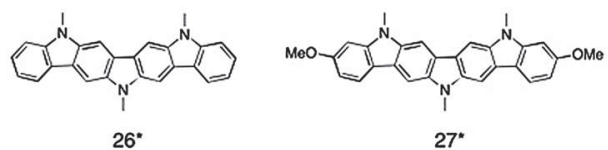

$27^{*}$
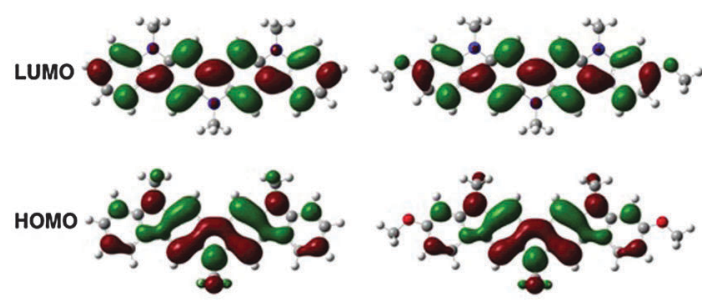

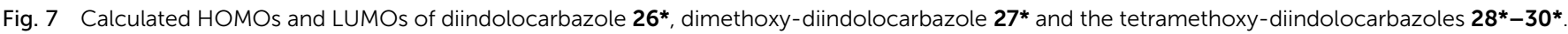

Table 5 Calculated HOMO and HOMO-LUMO gap for compounds $31^{*}-32^{*}$ and estimates for experimental values using correlations from Fig. $6^{a}$

\begin{tabular}{|c|c|c|c|c|}
\hline \multicolumn{3}{|c|}{ Calculated values $^{a}$} & \multicolumn{2}{|c|}{ Predicted experimental values } \\
\hline Comp. & HOMO (eV) & Band gap $(\mathrm{eV})$ & HOMO $(e V)$ & Band gap (eV) \\
\hline 31* & -4.706 & 3.436 & -5.074 & 2.680 \\
\hline $32^{*}$ & -4.727 & 3.265 & -5.088 & 2.550 \\
\hline $33^{*}$ & -4.768 & 3.332 & -5.117 & 2.601 \\
\hline
\end{tabular}

${ }^{a} \mathrm{~B} 3 \mathrm{LYP} / 6-31 \mathrm{G}(\mathrm{d})$ in $\mathrm{CH}_{2} \mathrm{Cl}_{2} \cdot{ }^{b}$ Using the appropriate correlations from Fig. 6.

making these heteroatom extended molecular versions of heteroacenes challenging synthetic targets.

\section{Conclusions}

Consecutive twofold Suzuki, Cadogan, and $\mathrm{N}$-alkylation reactions serve as step-economic and efficient sequences for the rapid construct of the diindolo $\left[3,2-b: 2^{\prime}, 3^{\prime}-h\right]$ carbazole framework. Besides the parent non-substituted diindolocarbazole 26, four new diindolo[3,2- $\left.b: 2^{\prime}, 3^{\prime}-h\right]$ carbazoles bearing two or four methoxy groups at different positions have been selectively synthesized. The developed synthetic sequence for diindolo[3,2$\left.b: 2^{\prime}, 3^{\prime}-h\right]$ carbazoles is appealing by both, the number of synthetic steps and the overall yield. It advances the chemistry of 7-ring linear fused diindolocarbazoles as potential materials for organic electronics. The physicochemical properties and MO calculations of methoxy-substituted diindolo[3,2- $\left.b: 2^{\prime}, 3^{\prime}-h\right]$ carbazoles reveal that the number and substitution pattern of methoxy groups significantly affect their electronic properties. Methoxy groups introduced at the 2,11- and 4,9-position have a direct influence on the electronic structures and increase the HOMO-energy levels in comparison to the parent non-substituted system. The observed changes in HOMO-LUMO energies caused by the methoxy substituents can serve as the fine-tuning of optical end electronic properties. Even using a very cost effective B3LYP/6-31G(d) $\left(\mathrm{CH}_{2} \mathrm{Cl}_{2}\right)$ DFT calculation a good linear correlation was observed between calculated and experimentally measured energies of the HOMO and HOMO-LUMO gaps.

The photoluminescence properties of diindolocarbazoles 26-30 in solution are characterized by light emission in the blue to blue-green region $\left({ }^{\mathrm{em}} \lambda=430-530 \mathrm{~nm}\right)$ with quantum yields of $\phi_{\mathrm{F}}=0.2-0.3$.

1,4,9,12-tetramethoxy-diindolo[3,2- $\left.b: 2^{\prime}, 3^{\prime}-h\right]$ carbazole 28 is the first diindolocarbazole reported with noticeable photoluminescence from the solid state. In comparison to the blue light emission in solution the photoluminescence of solid 28 is significantly red-shifted resulting in bright yellow fluorescence ( ${ }^{\mathrm{em}} \lambda=530-650 \mathrm{~nm}$ ) and a photoluminescence peak maxima at ${ }^{\mathrm{em}} \lambda_{\text {max }}=562 \mathrm{~nm}$. This excimer-type emission from solid 28 is distinguishable from the poor solid state photoluminescence of the other investigated diindolocarbazoles (26, 27, 29 and 30) in this series and underlines that $N$-alkyl and methoxy-group substitution patterns are critical to balance excimer-type emission and aggregate caused quenching effects by favouring the former.

The highest HOMO energy level for this set of compounds was found for 2,4,9,11-tetramethoxy-diindolo[3,2- $\left.b: 2^{\prime}, 3^{\prime}-h\right]$ carbazole (29) both by empirical and computational methods. By chemical comprehension this result can be understood such as that methoxy-substituents in the para- and ortho-position to a carbazole nitrogen (i.e. the positions of favourable electrophilic aromatic substitution in carbazoles) contribute the most to the increase of the electron density of the aromatic system.

Light emission properties as well as low-energy HOMO levels of $-5.06 \mathrm{eV}$ to $-4.92 \mathrm{eV}$ found for the diindolo[3,2- $\left.b: 2^{\prime}, 3^{\prime}-h\right]-$ carbazoles 26-30 make them potentially suitable for hole injection and hole transport in a thin-film based electronic device (OFET or OLED) - as well as it should guarantee a reasonable long-term stability.

\section{Acknowledgements}

The authors thank the European Regional Development Fund (ERDF) for funding as part of the Interreg IV A project MEET (Materials for Energy Efficiency in Transport). Support from the Ministère de l'Enseignement Supérieur et de la Recherche, France, for T.-H. Doan and E. Da Silva is gratefully acknowledged. We acknowledge the use of the IRIDIS High Performance Computing Facility and associated support services at the University of Southampton. 


\section{Notes and references}

1 (a) J. Roncali, P. Leriche and P. Blanchard, Adv. Mater., 2014, 26, 3821; (b) C. Wang, H. Dong, W. Hu, Y. Liu and D. Zhu, Chem. Rev., 2012, 112, 2208; (c) A. Mishra and P. Bäuerle, Angew. Chem., Int. Ed., 2012, 51, 2020; (d) Organic Electronics Emerging Concepts and Technology, ed. F. Cicoria and C. Santato, Wiley-VCH, 2013; (e) Organic Electronics - An Industrial Perspective, ed. H. Klauk, Wiley-VCH, 2006.

2 (a) J. Wang, F. Zhang, W. Tang, A. Tang, H. Peng, Z. Xu, F. Teng and Y. Wang, J. Photochem. Photobiol., C, 2013, 17, 69; (b) H. Zi, M. L. Senatore, M. E. Roberts, C. Reese, A. B. Mallik, S. C. B. Mannsfield, Z. Bao and J. Locklin, Organic Field-Effect Transistors, CRC Press, 2007; (c) Organic Light-Emitting Devices, ed. K. Müllen and U. Scherf, WileyVCH, 2006; (d) S. Allard, M. Forster, B. Souharce, H. Thiem and U. Scherf, Angew. Chem., Int. Ed., 2008, 47, 4070.

3 (a) J. Mei, Y. Diao, A. L. Appleton, L. Fang and Z. Bao, J. Am. Chem. Soc., 2013, 135, 6724; (b) M. E. Roberts, S. C. B. Mannsfeld, N. Queraltó, C. Reese, J. Locklin, W. Knoll and Z. Bao, Proc. Natl. Acad. Sci. U. S. A., 2008, 105, 1234; (c) H. Klauk, M. Halik, U. Zschieschang, G. Schmid, W. Radlik and W. Weber, J. Appl. Phys., 2002, 92, 5259.

4 (a) D. Simeone, S. Cipolloni, L. Mariucci, M. Rapisarda, A. Minotti, A. Pecora, M. Cuscuna, L. Maiolo and G. Fortunato, Thin Solid Films, 2009, 517, 6283; (b) K. Takimiya, T. Yamamoto, H. Ebata and T. Izawa, Sci. Technol. Adv. Mater., 2007, 8, 273.

5 For selected reviews, see: (a) W. Jiang, Y. Li and Z. Wang, Chem. Soc. Rev., 2013, 42, 6113; (b) C. Wang, H. Dong, W. Hu, Y. Liu and D. Zhu, Chem. Rev., 2012, 112, 2208; (c) Z. Sun, Q. Ye, C. Chi and J. Wu, Chem. Soc. Rev., 2012, 41, 7857; (d) K. Takimiya, S. Shinamura, I. Osaka and E. Miyazaki, Adv. Mater., 2011, 23, 4347; (e) A. Fukazawa and S. Yamaguchi, Chem. - Asian J., 2009, 4, 1386; $(f)$ J. E. Anthony, Angew. Chem., Int. Ed., 2008, 47, 452; (g) M. A. R. C. Murphy and J. M. J. Frechet, Chem. Rev., 2007, 107, 1066; (h) S. Yamaguchi, C. Xu and T. Okamoto, Pure Appl. Chem., 2006, 78, 721; (i) J. E. Anthony, Chem. Rev., 2006, 106, 5028; (j) M. Bendikov, F. Wudl and D. F. Perepichka, Chem. Rev., 2004, 104, 4891.

6 (a) Y. Xiong, X. Qiao, H. Wu, Q. Huang, Q. Wu, J. Li, X. Gao and H. Li, J. Org. Chem., 2014, 79, 1138; (b) G. Balaji, D. I. Phua, W. L. Shim and S. Valiyaveettil, Org. Lett., 2010, 12, 232; (c) P. Gao, X. Feng, X. Yang, V. Enkelmann, M. Baumgarten and K. Müllen, J. Org. Chem., 2008, 73, 9207; (d) T. Okamoto, K. Kudoh, A. Wakamiya and S. Yamaguchi, Org. Lett., 2005, 7, 5301; (e) S. Wakim and M. Leclerc, Synlett, 2005, 1223.

7 P.-L. T. Boudreault, S. Wakim, N. Blouin, M. Simard, C. Tessier, Y. Tao and M. Leclerc, J. Am. Chem. Soc., 2007, 129, 9125.

8 (a) M. Reig, J. Puigdollers and D. Velasco, J. Mater. Chem. C, 2015, 3, 506; (b) P.-L. T. Boudreault, A. A. Virkar, Z. Bao and M. Leclerc, Org. Electron., 2010, 11, 1649; (c) P.-L. T. Boudreault, S. Wakim, M. L. Tang, Y. Tao, Z. Bao and M. Leclerc, J. Mater. Chem., 2009, 19, 2921; (d) Y. Wu,
Y. Li, S. Gardner and B. S. Ong, J. Am. Chem. Soc., 2005, 127, 614; (e) Y. Li, Y. Wu, S. Gardener and B. S. Ong, Adv. Mater., 2005, 17, 849; $(f)$ S. Wakim, J. Bouchard, M. Simard, N. Drolet, Y. Tao and M. Leclerc, Chem. Mater., 2004, 16, 4386.

9 (a) C.-C. Lai, M.-J. Huang, H.-H. Chou, C.-Y. Liao, P. Rajamalli and C.-H. Cheng, Adv. Funct. Mater., 2015, 25, 5548; (b) H.-C. Ting, Y.-M. Chen, H.-W. You, W.-Y. Hung, S.-H. Lin, A. Chaskar, S.-H. Chou, Y. Chi, R.-H. Liu and K.-T. Wong, J. Mater. Chem., 2012, 22, 8399; (c) H.-P. Zhao, X.-T. Tao, P. Wang, Y. Ren, J.-X. Yang, Y.-X. Yan, C.-X. Yuan, H.-J. Liu, D.-C. Zou and M.-H. Jiang, Org. Electron., 2007, 8, 673.

10 (a) W. Ni, X. Wan, M. Li, Y. Wang and Y. Chen, Chem. Commun., 2015, 51, 4936; (b) X. Lin, Y. Tani, R. Kanda, K. Nakayama and S. Yagi, J. Mater. Chem. A, 2013, 1, 14686.

11 (a) Y. Xing, B. Hu, Q. Yao, P. Lu and Y. Wang, Chem. - Eur. J., 2013, 19, 12788; (b) J. H. Park, H. S. Lee, S. Park, S.-W. Min, Y. Yi, C.-G. Cho, J. Han, T. W. Kim and S. Im, Adv. Funct. Mater., 2013, 24, 1109.

12 S.-L. Suraru, C. Burschka and F. Würthner, J. Org. Chem., 2014, 79, 128.

13 M. Màs-Montoya, R. P. Ortiz, D. Curiel, A. Espinosa, M. Allain, A. Facchetti and T. J. Marks, J. Mater. Chem. C, 2013, 1, 1959.

14 (a) J. Schädlich, M. Wieteck, M. Rudolph, M. H. Larsen and S. K. Hashmi, Tetrahedron, 2015, 71, 5858; (b) D. Curiel, M. Más-Montoya, A. Uruvakili, R. A. Orenes, H. Pallamreddy and P. Molina, Org. Lett., 2010, 12, 3164.

15 (a) D. Curiel, M. M. Montoya, M. Hummert, M. Riede and K. Leo, Org. Electron., 2015, 17, 28; (b) D. Curiel, M. MásMontoya, C.-H. Chang, P.-Y. Chen, C.-W. Tai and A. Tárraga, J. Mater. Chem. C, 2013, 1, 3421.

16 J.-Y. Balandier, N. Henry, J.-B. Arlin, L. Sanguinet, V. Lemaur, C. Niebel, B. Chattopadhyay, A. R. Kennedy, P. Leriche, P. Blanchard, J. Cornil and Y. H. Geerts, Org. Lett., 2013, 15, 302.

17 (a) K. Ivaniuk, V. Cherpak, P. Stakhira, Z. Hotra, B. F. Minaev, G. V. Baryshnikov, E. Stromylo, D. Volyniuk, J. V. Grazulevicius, A. Lazauskas, S. Tamulevicius, B. Witulski, M. E. Light, P. Gawrys, R. J. Whitby, G. Wiosna-Sałyga and B. Luszczynska, J. Phys. Chem. C, 2016, 120, 6206; (b) G. V. Baryshnikov, P. Gawrys, K. Ivaniuk, B. Witulski, R. J. Whitby, A. Al-Muhammad, B. Minaev, V. Cherpak, P. Stakhira, D. Volyniuk, G. Wiosna-Salyga, B. Luszczynska, A. Lazauskas, S. Tamulevicius and J. V. Grazulzvicius, J. Mater. Chem. C, 2016, 4, 5795.

18 J. Bouchard, S. Wakim and M. Leclerc, J. Org. Chem., 2004, 69, 5705.

19 S. Wakim, J. Bouchard, N. Blouin, A. Michaud and M. Leclerc, Org. Lett., 2004, 6, 3413.

20 (a) I. Lévesque, P.-O. Bertrand, N. Blouin, M. Leclerc, S. Zecchin, G. Zotti, C. I. Ratcliffe, D. D. Klug, X. Gao, F. Gao and J. S. Tse, Chem. Mater., 2007, 19, 2128; (b) N. Blouin, A. Michaud, S. Wakim, P.-L. T. Boudreault, M. Leclerc, B. Vercelli, S. Zecchin and G. Zotti, Macromol. Chem. Phys., 2006, 207, 166. 
21 H. Geng, Y. Niu, Q. Peng, Z. Shuai, V. Coropceanu and J.-L. Brédas, J. Phys. Chem., 2011, 135, 104703.

22 For reviews on the Suzuki reaction, see: (a) A. Suzuki, in Boronic Acids, ed. D. G. Hall, Wiley-VCH, 2005, p. 123; (b) For microwave accelerated Suzuki reactions, see: Microwaves in Organic and Medicinal Chemistry, ed. C. O. Kappe and A. Stadler, Wiley-VCH, 2005; (c) N. Miyaura, in MetalCatalyzed Cross-Coupling Reactions, Vol. 1, ed. A. de Meijere and F. Diederich, Wiley-VCH, 2004, p. 41; (d) A. Suzuki, in Modern Arene Chemistry, ed. D. Astruc, Wiley-VCH, 2002, p. 53.

23 For selected examples of Cadogan reactions, see: (a) P. J. Bunyan and J. I. G. Cadogan, Proc. Chem. Soc., 1962, 78; (b) J. I. G. Cadogan, Synthesis, 1969, 11; (c) I. Hughes, W. P. Nolan and R. A. Raphael, J. Chem. Soc., Perkin Trans. 1, 1990, 2475; (d) A. Kirstenmacher and K. Müllen, J. Heterocycl. Chem., 1992, 29, 1237; (e) T.-L. Ho and S.-Y. Hsieh, Helv. Chim. Acta, 2006, 89, 111; $(f)$ Y.-J. Cheng, C.-H. Chen, Y.-J. Ho, S.-W. Chang, H. A. Witek and C.-S. Hsu, Org. Lett., 2011, 13, 5484; (g) P. Gong, P. C. Xue, C. Qian, Z. Z. Zhang and R. Lu, Org. Biomol. Chem., 2014, 12, 6134; (h) P. Gong, J. B. Sun, P. C. Xue, C. Qian, Z. Z. Zhang, J. B. Sun and R. Lu, Dyes Pigm., 2015, 118, 27; (i) Y. Chen, W. Liang, W. H. Choi, J. Huang, Q. Dong, F. Zhu and J. Su, Dyes Pigm., 2015, 123, 196; $(j)$ P. Gong, L. Li, J. Sun, P. Xue and R. Lu, Tetrahedron Lett., 2016, 57, 1468.

24 (a) P. A. Wender, F. C. Bi, G. G. Gamber, F. Gosselin, R. D. Hubbard, M. J. C. Scanio, R. Sun, T. J. Williams and L. Zhang, Pure Appl. Chem., 2002, 74, 25; (b) P. A. Wender, M. P. Croatt and B. Witulski, Tetrahedron, 2006, 62, 7505 and ref. cited therein.

25 I. W. Davies, V. A. Guner and K. N. Houk, Org. Lett., 2004, 6, 743.

26 A. W. Freeman, M. Urvoy and M. E. Criswell, J. Org. Chem., 2005, 70, 5014.

27 R. Sanz, J. Escibano, M. R. Pedrosa, R. Aguado and F. J. Arnáis, Adv. Synth. Catal., 2007, 349, 713.

28 (a) P. Appukkuttan, E. van der Eycken and W. Dehaen, Synlett, 2005, 127; (b) J. T. Kuethe and K. G. Childers, Adv. Synth. Catal., 2008, 350, 1577; (c) E. C. Creencia, M. Kosaka, T. Muramatsu, M. Kobayashi, T. Iizuka and T. Horaguchi, J. Heterocycl. Chem., 2009, 46, 1309.

29 For Cadogan reactions with heteroaromatics, see: (a) F. Baert, C. Cabanetos, M. Allain, V. Silvestre, P. Leriche and P. Blanchard, Org. Lett., 2016, 18, 1582; (b) S. Ghosh, A. Bedia and S. S. Zade, RSC Adv., 2015, 5, 5312; (c) T. Qi, Y. Guo, Y. Liu, H. Xi, H. Zhang, X. Gao, Y. Liu, K. Lu, C. Du, G. Yu and D. Zhu, Chem. Commun., 2008, 6227; (d) M. Mézlovà, J. J. Aaron, J. Svoboda, A. Adenier, F. Maurel and K. Chane-Ching, J. Electroanal. Chem., 2005, 581, 93; (e) ref. $6 d$ and $28 a$.
30 (a) M. Belletête, G. Durocher, S. Hamel, M. Côté, S. Wakim and M. Leclerc, J. Chem. Phys., 2005, 122, 104303; (b) M. Belletête, S. Wakim, M. Leclerc and G. Durocher, THEOCHEM, 2006, 760, 147.

31 (a) J. B. Birks, Photophysics of Aromatic Molecules, Wiley, New York, 1970; (b) J. Mei, N. L. C. Leung, R. T. K. Kwok, J. W. Y. Lam and B. Z. Tang, Chem. Rev., 2015, 115, 11718; (c) Y. Hong, J. W. Y. Lam and B. Z. Tang, Chem. Soc. Rev., 2011, 40, 5361.

32 (a) J. Kalinowski, Mater. Sci. - Pol., 2009, 27, 735; (b) J. Lee, B. Kim, J. E. Kwon, J. Kim, D. Yokoyama, K. Suzuki, H. Nishimura, A. Wakamiya, S. Y. Park and J. Park, Chem. Commun., 2014, 50, 14145; (c) H. Liu, L. Yao, B. Li, X. Chen, Y. Gao, S. Zhang, W. Li, P. Lu, B. Yang and Y. Ma, Chem. Commun., 2016, 52, 7356.

33 N. G. Connelly and W. E. Geiger, Chem. Rev., 1996, 96, 877. 34 C. M. Cardona, W. Li, A. E. Kaifer, D. Stockdale and G. C. Bazan, Adv. Mater., 2011, 23, 2367.

35 (a) A. D. Becke, J. Chem. Phys., 1993, 98, 5648; (b) C. Lee, W. Yang and R. G. Parr, Phys. Rev. B: Condens. Matter Mater. Phys., 1988, 37, 785; (c) P. J. Stephens, F. J. Devlin, C. F. Chabalowski and M. J. Frisch, J. Phys. Chem., 1994, 98, 11623.

36 R. Ditchfield, W. J. Hehre and J. A. Pople, J. Chem. Phys., 1971, 54, 724.

37 (a) V. Barone and M. Cossi, J. Phys. Chem. A, 1998, 102, 1995; (b) M. Cossi, N. Rega, G. Scalmani and V. Barone, J. Comput. Chem., 2003, 24, 669.

38 M. J. Frisch, G. W. Trucks, H. B. Schlegel, G. E. Scuseria, M. A. Robb, J. R. Cheeseman, G. Scalmani, V. Barone, B. Mennucci, G. A. Petersson, H. Nakatsuji, M. Caricato, X. Li, H. P. Hratchian, A. F. Izmaylov, J. Bloino, G. Zheng, J. L. Sonnenberg, M. Hada, M. Ehara, K. Toyota, R. Fukuda, J. Hasegawa, M. Ishida, T. Nakajima, Y. Honda, O. Kitao, H. Nakai, T. Vreven, J. A. Montgomery, Jr., J. E. Peralta, F. Ogliaro, M. Bearpark, J. J. Heyd, E. Brothers, K. N. Kudin, V. N. Staroverov, T. Keith, R. Kobayashi, J. Normand, K. Raghavachari, A. Rendell, J. C. Burant, S. S. Iyengar, J. Tomasi, M. Cossi, N. Rega, J. M. Millam, M. Klene, J. E. Knox, J. B. Cross, V. Bakken, C. Adamo, J. Jaramillo, R. Gomperts, R. E. Stratmann, O. Yazyev, A. J. Austin, R. Cammi, C. Pomelli, J. W. Ochterski, R. L. Martin, K. Morokuma, V. G. Zakrzewski, G. A. Voth, P. Salvador, J. J. Dannenberg, S. Dapprich, A. D. Daniels, O. Farkas, J. B. Foresman, J. V. Ortiz, J. Cioslowski and D. J. Fox, Gaussian 09, Revision D.01, Gaussian, Inc, Wallingford CT, 2013.

39 (a) C.-G. Zhan, J. A. Nichols and D. A. Dixon, J. Phys. Chem. A, 2003, 107, 4184; (b) D. D. Méndez-Hernández, P. Tarakeshwar, D. Gust, T. A. Moore, A. L. Moore and V. Mujica, J. Mol. Model., 2013, 19, 2845. 